\title{
The Importance of Self-Mastery in Enhancing Quality of Life and Social Participation of Individuals Experiencing Homelessness: Results of a Mixed-Method Study
}

\author{
Miranda Rutenfrans-Stupar ${ }^{1,2,3} \cdot$ Naomi Hanique ${ }^{1,2,3} \cdot$ Tine Van Regenmortel $^{1,4}$. \\ René Schalk ${ }^{1,5}$
}

Accepted: 17 October 2019 / Published online: 25 October 2019

(c) The Author(s) 2019

\begin{abstract}
Self-mastery plays a basic role in strength-based and recovery-oriented approaches applied by (mental) health-care institutions and social services. However, no research has been conducted on a comprehensive model that could provide insight into enhancing self-mastery and outcomes, such as social participation and quality of life, for individuals experiencing homelessness. The current mixed-method study investigated associations between person-related variables (optimism, age, education level) and care-related variables (experiences with care, duration of support) as predictors of both social participation and quality of life through the mediator of self-mastery among clients of a Dutch shelter facility. Quantitative analysis (Structural Equation Modeling; $n=97$ ) showed that: (1) Self-mastery is related to social participation and quality of life; (2) Optimism predicts social participation and quality of life through self-mastery; (3) Age squared predicts social participation through self-mastery, but is not related to quality of life; (4) The variable, clients' experiences with care, is not related to self-mastery, but directly to social participation and quality of life; (5) Education level and duration of support do not predict self-mastery, social participation and quality of life. Qualitative analysis (semi-structured interviews; $n=36$ ) revealed: (1) Contrary to the results of the quantitative study qualitative data indicated that there is a positive association between experiences with care and self-mastery; (2) Social participation and health are associated with self-mastery; (3) The absence of external locus of control should also be included as an aspect of self-mastery; (4) Additional promoting and impeding factors for self-mastery (e.g., a daily structure, privacy, house rules). Based on these results we formulated guidelines for social and mental health-care workers to enhance their clients' self-mastery.
\end{abstract}

Keywords Self-mastery · Homelessness - Social participation · Quality of life $\cdot$ Mixedmethod study

Miranda Rutenfrans-Stupar

mirandarutenfrans@yahoo.com

Extended author information available on the last page of the article 


\section{Introduction}

Self-mastery is a high priority issue in the Netherlands. The Dutch government aims to promote self-mastery among citizens, which implies that they should take responsibility for their own life. This is related to the concept of the "participation society" in which citizens are encouraged to take care of themselves and each other, so that applying for state support is seen as a last resort (Van Houten et al. 2008; Rijksoverheid 2013). Hence, the role of government is changing: People are given more responsibility and are enabled to take more initiatives themselves, rather than relying on the presence of a large government that regulates numerous matters and is constantly involved in all aspects of daily life. This implies that people need to be capable of mastering their life. For individuals experiencing homelessness this is not obvious, as they are often caught up in negative life events and social exclusion leading to a dysfunction of their self-regulation skills (Wolf 2016), which makes it difficult for this group to master their lives.

For (mental) health-care institutions and social services, including organizations providing shelter and ambulatory care for individuals experiencing homelessness (i.e., shelter facilities), the transformation into a participation society has significant consequences. Workers of these organizations cannot support their clients in the way they used to do. They need to shift their focus more toward helping clients accomplish social participation and self-mastery instead of focusing on problems and facilitating clients to live in residential shelters. This means that clients should not be institutionalized for extended periods of time and that they are encouraged to build social contacts and to participate in all kinds of activities. In other words; they should live life like most people do.

In this perspective, empowerment plays a central role. Empowerment can be defined as "a process by which people, organizations, and communities gain mastery over issues of concern to them" (Rappaport 1987, p. 122). At an individual level this construct is defined as "psychological empowerment", which combines "perceptions of personal control, a proactive approach to life, and a critical understanding of the sociopolitical environment" (Zimmerman 1995, p. 581). The latter refers to understanding how systems function within a context and being able to behave in such a way that one can influence that context, which is closely related to social participation. The construct of empowerment includes a personality component in which "internal locus of control" plays a role, a cognitive component that includes "self-efficacy", and a motivational component that includes "the desire for control" (Zimmerman 1995; Van Regenmortel 2002).

The founders of the concept of self-mastery, Pearlin and Schooler (1978, p. 5), defined self-mastery as "the extent to which one regards one's life-chances as being under one's own control in contrast to being fatalistically ruled". We broadened this definition to a more modern construct consistent with government policy and with the operationalization of empowerment; namely as the desire to determine one's own life including the beliefs that one is able to do this and also feels responsible for it. Hence, self-mastery is a combination of intrinsic motivation (the desire to act in a certain way because it is interesting and satisfying in itself; Deci and Ryan 1985), self-efficacy (the belief in one's ability to achieve goals including the belief in one's ability to cope with various stressful or challenging demands; Bandura 1977; Luszczynska et al. 2005), and internal locus of control (the belief in one's ability to control the outcomes of life events; Rotter 1966). 


\subsection{Predictors of Self-Mastery, Social Participation, and Quality of Life}

Self-mastery, social participation, and quality of life can be influenced by person-related predictors (e.g., personality, age and education level) and care-related predictors (e.g., experiences with care and duration of support). Results of a previous study show that social participation and well-being are positively influenced by clients' experiences with care (i.e., satisfaction with the services received and satisfaction with the client-worker relationship) and education level (Rutenfrans-Stupar et al. 2019a). Education level is also positively related to self-mastery (Forbes 2001; Dalgard et al. 2007). Strengthbased and recovery-oriented approaches (e.g., Den Hollander and Wilken 2013; Korevaar and Dröes 2016; Wolf 2016; Rutenfrans-Stupar et al. 2019b) assume that the social worker plays a key role in enhancing clients' self-mastery, which implies that the clients' satisfaction with the client-worker relationship can also be viewed as a predictor of self-mastery. Furthermore, these approaches also assume that the worker must be clear about what clients can expect from the shelter facility (e.g., Den Hollander and Wilken 2013; Korevaar and Dröes 2016; Wolf 2016; Rutenfrans-Stupar et al. 2019b), which is a relevant aspect of clients' experiences with care.

Another care-related predictor is the duration of support, which is the amount of time that clients are supported by the shelter facility. Clients with a longer duration of support probably have more complex care demands and are expected to be at a higher risk of institutionalization, which in turn leads to lower levels of self-mastery, social participation, and quality of life (Rapp and Goscha 2012).

We previously mentioned education level as a person-related predictor that can influence self-mastery, social participation and quality of life, but there are other personrelated predictors as well. For example, research shows that a person's level of optimism is positively correlated with two components of self-mastery, namely self-efficacy (Posadzki et al. 2010) and internal locus of control (Gruber-Baldini et al. 2009). Moreover, optimism is positively related to quality of life (Schou et al. 2005; Gruber-Baldini et al. 2009; Applebaum et al. 2013) and to social support or social functioning (Schou et al. 2005; Applebaum et al. 2013).

Further, age is positively related to two aspects of self-mastery, namely to internal locus of control (Knoop 1981; Chubb et al. 1997) and partly to self-efficacy (Woodward and Wallston 1987). It seems that self-efficacy increases with age, but at a certain (older) age it starts to diminish again. This is also consistent with research on the relationship between social participation and age: At a certain age people will participate less in activities and have fewer friends, because friendships end or friends pass away (Wallace and Pichler 2009; Eurostat 2010). The relationship between age and quality of life is unclear, but it is possible that age correlates with quality of life until a certain age (Diener 2009). Therefore, if age is associated with self-mastery, social participation, and quality of life, we expect this relationship to be quadratic.

Lastly, we treated self-mastery as a mediator between client-related and care-related predictors on the one hand and social participation and quality of life on the other. This is in line with previous research in which self-mastery also mediated the relationship between some of the variables we included in our study (e.g., Dalgard et al. 2007; Kan et al. 2012). However, to our knowledge there are no previous studies that examined the role of self-mastery in the relationship between both person- and care-related predictors and the two outcome variables (i.e., social participation and quality of life.) 


\subsection{The Current Study}

The current study aims to: (1) test a structural equation model exploring associations between person-related and care-related variables as predictors of social participation and quality of life through the mediator of self-mastery (Fig. 1); (2) explain and interpret the model by using qualitative study findings from interviews with individuals experiencing homelessness. With the knowledge on (predictors of) self-mastery in relation social participation and quality of life, organizations (such as shelter facilities) are enabled to develop a recovery-oriented program that promotes sustainable social participation and quality of life among individuals experiencing homelessness.

\section{Methods}

\subsection{Design and Participants}

In general, in the Dutch context "all people who receive support from the shelter facility" are defined as homeless or houseless persons (e.g., Kruize and Bieleman 2014; Planije et al. 2014). This definition also applies to people who do have their own dwelling, but are still at risk of homelessness mostly due to debts or their (mental) health condition (Tuynman and Planije 2012; McQuistion et al. 2013). This differs from the European definition of homelessness, which applies only to people who are roofless, houseless (for example residential clients of a shelter facility), or living in insecure or in inadequate housing (Feantsa 2005). In the current study we use the term "individuals experiencing homelessness", which includes residential and ambulatory clients of the shelter facility. Residential clients are persons who live in one of the shelters, and ambulatory clients are persons who have their own dwelling but were homeless in the past or are at serious risk of losing their dwelling.

We used a mixed-method design, namely a "convergent parallel design" (Creswell and Plano Clark 2011), consisting of quantitative and qualitative research among clients of a Dutch shelter facility (i.e., SMO Breda e.o.). Both studies were conducted among all four shelters of this facility and included clients receiving ambulatory care. The quantitative and qualitative study took place simultaneously and we merged the results for comparison after both data collections. Consequently, both studies were prioritized

Fig. 1 Hypothesized model of self-mastery

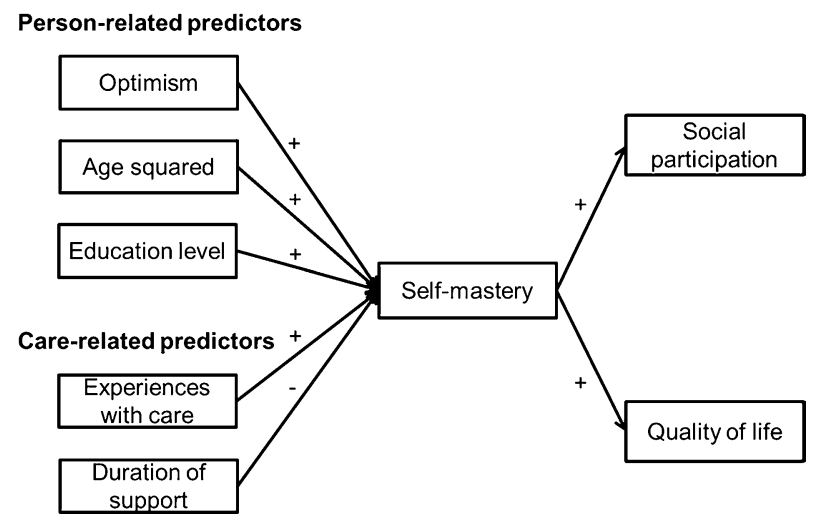


equally, data were kept independent during the data collection, and results were finally synthesized during the overall interpretation of the data. For both studies we used the following inclusion criteria for the eligible participants: (1) at least 18 years old; (2) understanding Dutch language; (3) able to give informed consent; (4) able to fill out a questionnaire or to be interviewed. Of the total population (measured on 1 April 2018) of 391 clients, 67 clients seemed not eligible, because they either did not meet the selection criteria or were temporarily absent (e.g., were staying in hospital or detention), resulting in 324 eligible clients. Clients were allowed to participate in both studies (21 clients participated in both studies). All clients who participated in the current study gave written informed consent. Clients received a compensation of $€ 2,50$ when they participated in an interview or filled out a questionnaire. This amount of money is similar to the regular compensation they receive for voluntary work (i.e., labor-related activities) for one day part. The research protocol was approved by the Ethics Review Board of Tilburg University (EC-2018.12) before the study started. The data were collected between 16 April and 12 June 2018.

The quantitative study had a cross-sectional study design. We used a convenience sampling technique (Etikan 2016), where all eligible clients from the shelter facility were invited to participate in the quantitative study. Ambulatory clients received a written questionnaire which they could fill out independently, but assistance was provided if requested (two clients were assisted during an interview; 42 filled out the questionnaire). Residential clients were preferably interviewed $(n=47)$, but could fill out a questionnaire if they preferred $(n=6)$. Ninety-seven clients participated (30\% of eligible participants) of which 53 residential clients and 44 ambulatory clients (respectively $36 \%$ of eligible residential clients and $25 \%$ of eligible ambulatory clients). Most participating clients were male (72\%), were aged in the category 50 to 70 years $(53 \%)$, had lower $(35 \%)$ or intermediate education (38\%), and their duration of support was 1 to 5 years (44\%) (see Table 1).

The qualitative study consisted of 36 semi-structured interviews. We used a purposive sampling technique (Etikan 2016) by applying the following procedure. First, to obtain a representative sample the interviewers determined the number of clients that needed to be interviewed per demographic category, namely gender, age, duration of support, and residential situation. Second, the interviewers went to the different shelter residences to ask who would be willing to participate in an interview, and to check whether the willing clients met the selection criteria and the criteria regarding representativeness. In case more people of one representative group wanted to participate, the person who first registered was selected. Finally, to complete our representative sample we also asked the social/community workers if they knew people who met the criteria. The workers had no additional role in the interviews. The average duration of the interviews with clients was $40 \mathrm{~min}$. Most of the participating clients were male $(83 \%)$, were aged 50 to 70 years $(47 \%)$, had lower $(25 \%)$ or intermediate education (25\%), were living in their own dwelling (53\%), and their duration of support was five years or more (44\%) (see Table 1). The quantitative and qualitative sample formed an accurate representation of the population of clients of the shelter facility (all $\chi^{2}$ values were non-significant).

The interviewers of both the quantitative and qualitative research had an education background in social work or health care, and were trained in interviewing individuals experiencing homelessness before the data collection started. The interviewers were independent, i.e., they did not have a role in the support of clients of the shelter facility where the research was conducted and were not an employee of the shelter facility. 
Table 1 Demographic variables of clients

\begin{tabular}{|c|c|c|c|c|}
\hline Demographics & $\begin{array}{l}\text { Quantitative study } \\
(n=97)\end{array}$ & $\begin{array}{l}\text { Qualitative study } \\
(n=36)\end{array}$ & $\begin{array}{l}\text { Population } \\
\text { of the shelter } \\
\text { facility } \\
(N=391)^{\mathrm{a}}\end{array}$ & Chi square \\
\hline \multicolumn{5}{|l|}{ Gender } \\
\hline Male & $72(74 \%)$ & $30(83 \%)$ & $300(77 \%)$ & \multirow[t]{2}{*}{$1.22^{\text {n.s. }}$} \\
\hline Female & $25(26 \%)$ & $6(17 \%)$ & $91(23 \%)$ & \\
\hline \multicolumn{5}{|l|}{ Age $^{b}$} \\
\hline $18-30$ years & $7(7 \%)$ & $2(6 \%)$ & $42(11 \%)$ & \multirow[t]{4}{*}{$5.22^{\text {n.s. }}$} \\
\hline $30-50$ years & $33(34 \%)$ & $14(39 \%)$ & $160(41 \%)$ & \\
\hline $50-70$ years & $51(53 \%)$ & $17(47 \%)$ & $161(41 \%)$ & \\
\hline$\geq 70$ years & $6(6 \%)$ & $3(8 \%)$ & $27(7 \%)$ & \\
\hline \multicolumn{5}{|l|}{ Education level } \\
\hline $\begin{array}{l}\text { No education or primary educa- } \\
\text { tion }\end{array}$ & $16(17 \%)$ & $1(3 \%)$ & $\mathrm{n} / \mathrm{a}^{\mathrm{c}}$ & \multirow[t]{5}{*}{$6.54^{\text {n.s. }}$} \\
\hline Lower education & $34(35 \%)$ & $9(25 \%)$ & $\mathrm{n} / \mathrm{a}^{\mathrm{c}}$ & \\
\hline Intermediate education & $37(38 \%)$ & $9(25 \%)$ & $\mathrm{n} / \mathrm{a}^{\mathrm{c}}$ & \\
\hline \multirow[t]{2}{*}{ Higher education Missing } & $10(10 \%)$ & $7(19 \%)$ & $\mathrm{n} / \mathrm{a}^{\mathrm{c}}$ & \\
\hline & - & $10(28 \%)$ & $\mathrm{n} / \mathrm{a}^{\mathrm{c}}$ & \\
\hline \multicolumn{5}{|l|}{ Residential situation } \\
\hline $\begin{array}{l}\text { In own dwelling with ambulatory } \\
\text { care }\end{array}$ & $44(45 \%)$ & $19(53 \%)$ & $213(54 \%)$ & \multirow[t]{3}{*}{$3.22^{\text {n.s. }}$} \\
\hline $\begin{array}{l}\text { Residential shelter (long-term } \\
\text { stay) }\end{array}$ & $45(46 \%)$ & $14(39 \%)$ & $143(37 \%)$ & \\
\hline Shelter facility (short-term stay) & $8(8 \%)$ & $3(8 \%)$ & $35(9 \%)$ & \\
\hline \multicolumn{5}{|l|}{ Duration of support } \\
\hline$<1$ year & $22(23 \%)$ & $8(22 \%)$ & $100(26 \%)$ & \multirow[t]{3}{*}{$2.53^{\text {n.s. }}$} \\
\hline $1-5$ years & $43(44 \%)$ & $12(33 \%)$ & $147(38 \%)$ & \\
\hline$\geq 5$ years & $32(33 \%)$ & $16(44 \%)$ & $146(37 \%)$ & \\
\hline
\end{tabular}

${ }^{\mathrm{a} O n} 1$ April 2018

${ }^{\mathrm{b}} M_{\text {quantitative study }}=51.89(S D=13.05) ; M_{\text {qualitative study }}=51.33(S D=13.84)$

${ }^{\mathrm{c}}$ The management information system of the shelter facility did not include education level for the total population of the shelter facility

${ }^{\mathrm{n} . \mathrm{s}}$ Non-significant: $p>.05$

\subsection{Measures}

\subsubsection{Quantitative Study}

Demographic characteristics were assessed as shown in Table 1. Self-mastery was operationalized as a combination of self-efficacy, intrinsic motivation, and internal locus of control. To this end we used three instruments: (1) the General Self-Efficacy Scale (GSE) (Schwarzer and Jerusalem 1995), (2) the Situational Motivation Scale (SIMS) (Guay et al. 2000), and (3) Locus of Control (LOC) scale (Rotter 1966). The GSE had 
a Dutch version (Teeuw et al. 1997), but there were no Dutch versions of the SIMS and LOC scale available. Therefore, we used the back-translation method.

The GSE consists of 10 items that are scored on a 4-point Likert scale, ranging from 1 (not at all true) to 4 (exactly true). In the current study we used the total score. Additionally, we used an adapted version of the SIMS to measure motivation. The original scale aims to measure motivation to participate in activities. We generalized the original 16 items to measure motivation to master one's life. Answers could be scored on a 7-point Likert scale ranging from 1 (corresponds not all) to 7 (corresponds exactly), and for our analysis we used the mean scores. For the data analysis of the current study we used the subscale "Intrinsic Motivation". The last scale used to measure self-mastery, the LOC scale, consists of 29 items of which six are filler items. It is a forced-choice scale: For each item respondents have to choose between two statements. Higher scores represent a higher external locus of control (Rotter 1966). We reversed the total scores resulting in that higher scores represent a higher internal locus of control.

Optimism was assessed using the Dutch version of the Life Orientation Test-Revised (LOT-R) (Scheier et al. 1994; Ten Klooster et al. 2010), which is an instrument for assessing people's generalized sense of optimism. It consists of 10 items that can be scored on a 5-point Likert scale ranging from 0 (strongly disagree) to 4 (strongly agree). The three items that are negatively formulated form the subscale pessimism, the three items that are positively formulated form the subscale optimism, and the other four items are filler items (Scheier et al. 1994; Ten Klooster et al. 2010). We used the total score of the subscale optimism for our analysis.

Experiences with care were assessed using subscales of the Consumer Quality Index for Shelter and Community Care Services (CQI-SCCS) (Beijersbergen et al. 2010). We used the subscale "Services Received" consisting of eight items, the subscale "Client-Worker Relationship" consisting of four items, and the two items concerning "General Rating". The latter could be scored on a scale from 0 to 10; the items of the other two subscales were rated on a four-point Likert scale rating from 1 (never) to 4 (always). We calculated the mean scores for our analysis.

Social participation was assessed using the Community Integration Measure (CIM) (McColl et al. 2001). We used the Dutch translation provided by Van Luijtelaar and Wolf (2012). The CIM consists of 10 items that can be scored on a five-point Likert scale ranging from 1 (always disagree) to 5 (always agree). We calculated the total score for our analysis. We adapted the items slightly by using the term "society" instead of "community", because we sought to measure social participation in a broader context, while "community" can also be restricted to the location where people are living.

Quality of life was assessed using the Dutch version of the World Health Organization Quality of Life Brief version (WHOQOL-BREF) (De Vries and Van Heck, 1996; WHO 1998), consisting of 26 items and four subscales: "Physical Health", "Psychological Health", "Social Relationships", and "Environment". Answers could be given on a fivepoint Likert scale ranging from 1 (very poor or very dissatisfied) to 5 (very good or very satisfied). In the current study we used the total score of all subscales and transformed these scores to a $0-100$ scale.

\subsubsection{Qualitative Study}

Before conducting the semi-structured interviews, the main topics and most of the openended questions associated with these topics were formulated. Accordingly, we made an 
interview description (see Table 2) that included: (1) self-mastery related to the client's living situation, which included the subtopics of feeling at home, household chores, house rules (residential clients), contact with neighbors (ambulatory clients), and paying the rent and other bills (ambulatory clients); (2) self-mastery related to the client's personal trajectory, which included short- and long-term goals related to the living and social situation, and daily activities. We chose to specify self-mastery in terms of these two topics, because it is closely related to the personal situation of the clients. The following question is asked about every topic: "What influence do you have on this?" (which is probed further in relation to motivation, self-efficacy, locus of control). Additionally, the interviewers asked about promoting and impeding factors for every topic and how this relates to social participation and quality of life.

\subsection{Analyses}

\subsubsection{Quantitative Study}

We used SPSS (version 23) for descriptive statistics and scale reliabilities, and AMOS (version 22) (Arbuckle 2013) for Structural Equation Modeling to test the hypothesized mediation model (Fig. 1). We included latent and observed variables in our model. A latent variable is not observed directly, but represented by a combination of observed variables (Byrne 2016). In the current study we distinguished the following latent variables:

Experiences with care, self-mastery, and quality of life. Additionally, optimism, age squared and social participation were treated as observed variables.

We could not perform Confirmatory Factor Analysis (CFA), since CFA should be performed for at least 10 respondents per item (Schreiber et al. 2006; Blunch 2013). All scales used in the current study consisted of 10 or more items and only 97 participants were involved in the quantitative study.

Before conducting the analyses, we screened our data set for missing variables. Missing value analysis showed that less than $1 \%$ of the data of all variables used were missing. We investigated whether this had biased the data using Little's Missing Completely At Random (MCAR) test $\left(\chi^{2}=1642.130, d f=3922, p>.05\right)$, which showed that the missing data were completely at random. Hence, we concluded that the incomplete data sample is still representative of the hypothetically complete data (Little 1988). To obtain estimates of the parameters, we used the Full Information Maximum Likelihood (FIML) method, which is one of the best approaches to handle missing data (Enders and Bandalos 2001; Arbuckle 2013; Byrne 2016).

\subsubsection{Qualitative Study}

The interviews were recorded by using a voice-recorder, with permission of the participants, and then the interviews are transcribed verbatim (i.e., word-for-word). We used NVivo (QSR NVivo version 12) to store, organize and analyze qualitative data. The qualitative study contains both elements of deductive and inductive arguments (Hayes 2000; Teddlie and Tashakkori 2009). The deductive approach is reflected in that, as already described in Paragraph 2.2.2, the interview questions were formulated around themes in the hypothesized model (Hayes 2000; Teddlie and Tashakkori 2009). The actual analysis of qualitative data followed the inductive approach as described by Hayes (2000) where two researchers (1) identified meaningful units of text, (2) grouped and named units of text 


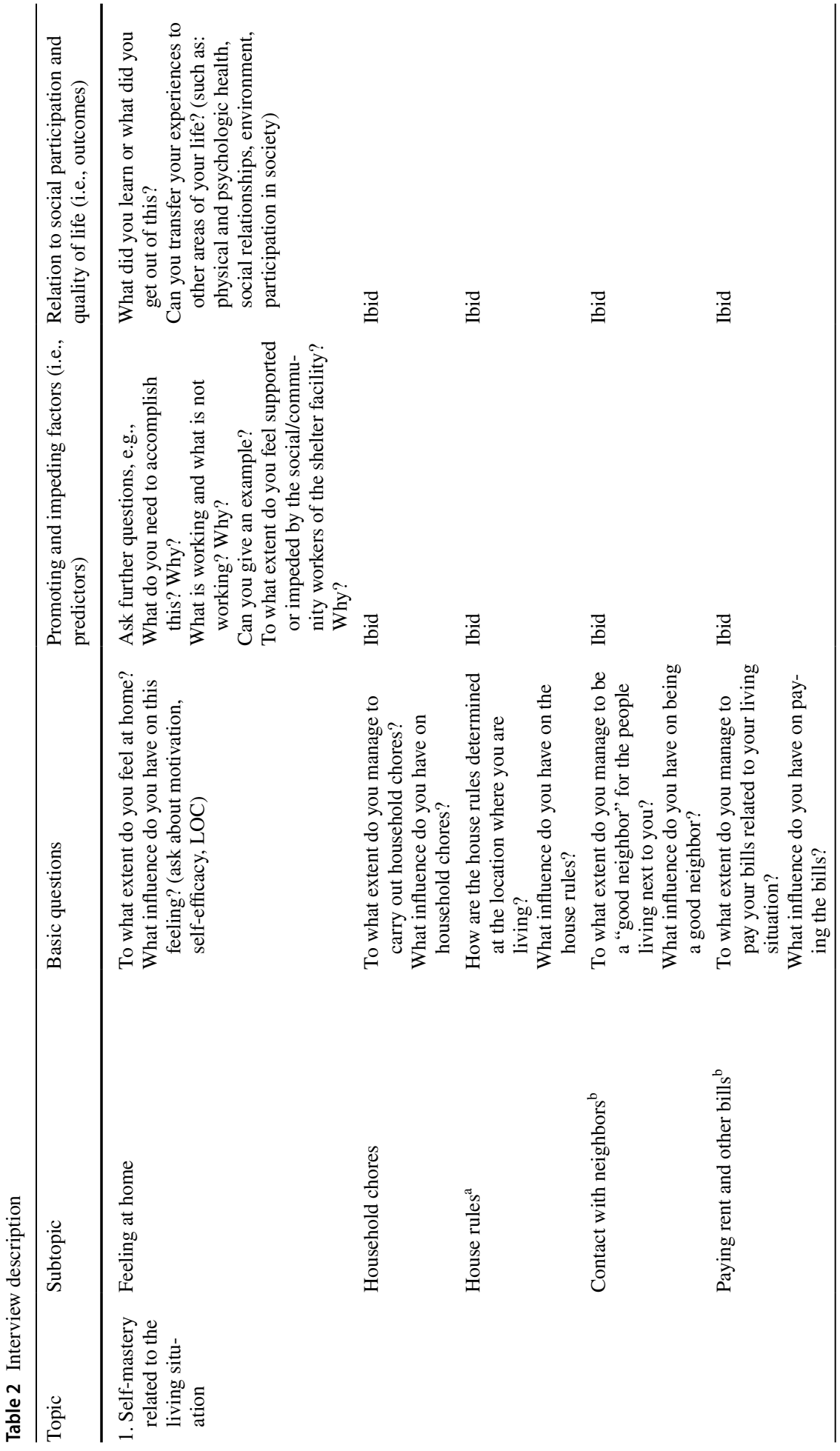




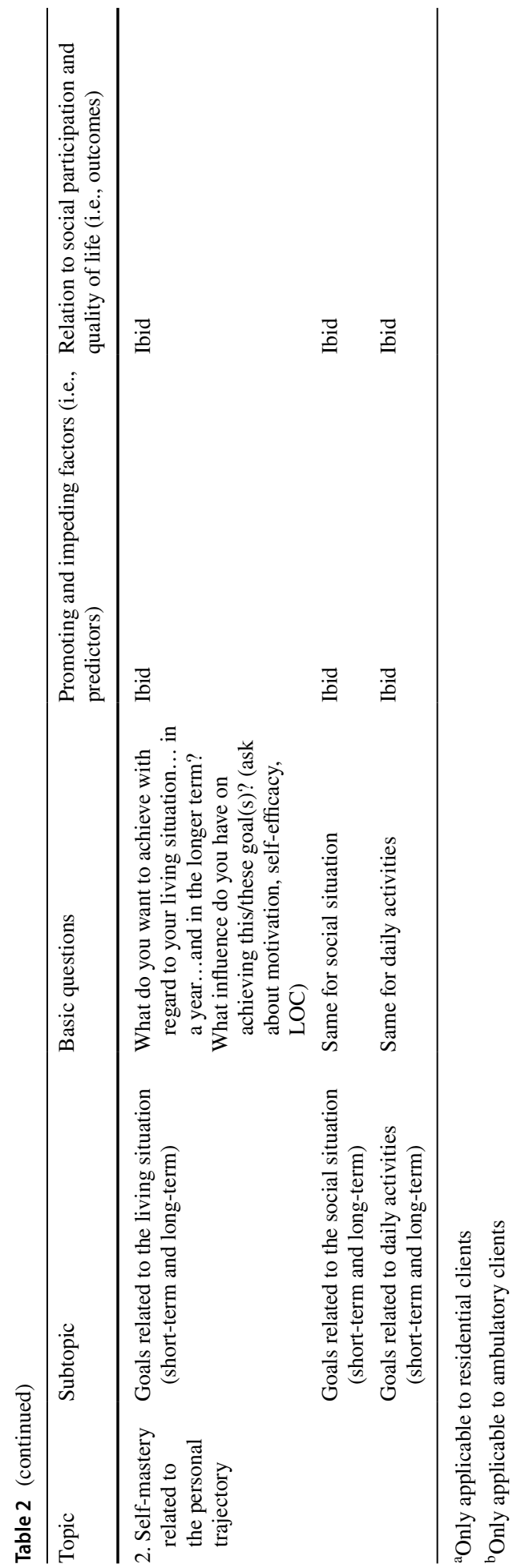


that were associated with each other into meaningful categories (nodes), and (3) clustered the categories into emerging themes. Note that two-third of the interviews were coded by two researchers while the rest was coded by one of them. Approximately $80 \%$ of the coding corresponded between the two coders. The second author of this paper did the second coding process and discussed significant differences between the two coding processes including categories and themes with the first author. We could not include whether age squared, education level, and duration of support enhance the levels of self-mastery, social participation, and quality of life, because for this type of analysis a quantitative approach is needed.

\section{Results}

\subsection{Quantitative Study}

The means and Cronbach's alphas (which were all satisfactory) of the variables concerning clients' experiences with care $\left(M_{\text {services received }}=3.14\right.$, Cronbach's $\alpha=.91$; $M_{\text {client-worker relationship }}=3.46$, Cronbach's $\alpha=.86$; and $M_{\text {general rating }}=7.71$, Cronbach's $\alpha=.88)$, optimism $(M=8.05$, Cronbach's $\alpha=.71)$ self-mastery $\left(M_{\text {intrinsic motivation }}=5.32\right.$, Cronbach's $\alpha=.83 ; M_{\text {self-efficacy }}=30.47$, Cronbach's $\alpha=.87$; and $M_{\text {internal locus of control }}=11.19$, Cronbach's $\alpha=.62)$, social participation $(M=36.66$, Cronbach's $\alpha=.84)$, and quality of life $\left(M_{\text {physical health }}=24.09\right.$, Cronbach's $\alpha=.82 ; M_{\text {psychological health }}=21.13$, Cronbach's $\alpha=.81$; $M_{\text {social relationships }}=10.17$, Cronbach's $\alpha=.67 ;$ and $M_{\text {environment }}=28.00$, Cronbach's $\alpha=.78$ ) are presented in Table 3.

To test the model, we first tested the hypothesized model without the mediator (selfmastery). This model had a fair fit $\left(\chi^{2} / d f=1.704, \mathrm{CFI}=.914, \mathrm{RMSEA}=.086\right)$ (criteria for 'good' model fit are: $\chi^{2} / d f<3.0$, CFI $>.90$, and RMSEA <.08; Awang 2012; Arbuckle 2013). However, in this model duration of support and education level were not significantly related to either quality of life or social participation, and age squared was only related to quality of life. The proportion variance explained for social participation was $32 \%$ and for quality of life $38 \%$.

Table 3 Means, standard deviations (in parentheses), and internal consistency coefficient (Cronbach's alpha)

\begin{tabular}{llcl}
\hline Scale & $n$ & Mean (SD) & $\alpha$ \\
\hline Services received & 86 & $3.14(.70)$ & .91 \\
Client-worker relationship & 96 & $3.46(.59)$ & .86 \\
General rating & 95 & $7.71(1.58)$ & .88 \\
Optimism & 95 & $8.05(2.45)$ & .71 \\
Intrinsic motivation & 97 & $5.32(1.25)$ & .83 \\
Self-efficacy & 95 & $30.47(5.80)$ & .87 \\
Internal locus of control & 84 & $11.19(3.46)$ & .62 \\
Social participation & 95 & $36.66(6.16)$ & .84 \\
Physical health (QoL) & 94 & $24.09(5.43)$ & .82 \\
Psychological health (QoL) & 91 & $21.13(4.25)$ & .81 \\
Social relationships (QoL) & 93 & $10.17(2.63)$ & .67 \\
Environment (QoL) & 86 & $28.00(5.21)$ & .78 \\
\hline
\end{tabular}


Second, we tested the hypothesized model with the mediator, but without the non-significant predictors (duration of support and education level). This model had a good fit $\left(\chi^{2} / d f=1.518, \mathrm{CFI}=.923, \mathrm{RMSEA}=.073\right)$. All relations between the variables were significant $(p<.05)$. The proportion variance explained for self-mastery was $44 \%$, for social participation $50 \%$, and for quality of life $85 \%$.

Third, we tested a model with the mediator which included, besides the indirect paths, also the direct paths from the predictors to the outcome variables. Both optimism $(\beta=.55$; $p<.001)$ and age squared $(\beta=.30 ; p<.05)$ predicted self-mastery significantly; and selfmastery significantly predicted social participation $(\beta=.68 ; p<.001)$ and quality of life $(\beta=.96 ; p<.001)$. However, the variable, experiences with care, was not significantly related to self-mastery $(\beta=-.02 ; p>.05)$. The direct effects of experiences with care on social participation $(\beta=.36 ; p<.001)$ and quality of life $(\beta=.29 ; p<.05)$ were significant, which leads to the finding that experiences with care is a direct predictor of social participation and quality of life. The direct effects of optimism on social participation $(\beta=-.04$; $p>.05)$ and on quality of life $(\beta=-.15 ; p>.05)$ were significant and smaller than the direct effects when the mediator (self-mastery) was not included in the model (these values were for social participation $\beta=.33 ; p<.001$, and for quality of life $\beta=.35 ; p<.001$ ). Additionally, the direct effect of age squared on quality of life $(\beta=-.05 ; p>.05)$ was significant and smaller than the direct effects when the mediator (self-mastery) was not included in the model $(\beta=.26 ; p<.05)$. However, the direct effect of age squared on social participation in the model with the mediator $(\beta=-.13 ; p>.05)$ was stronger compared to the model without the mediator $(\beta=.06 ; p>.05)$.

In conclusion, the variable, experiences with care, is directly related to social participation and quality of life. On the one hand, self-mastery is a full mediator of the relationship between optimism and both outcome variables (social participation and quality of life). On the other hand, self-mastery is a full mediator of the relationship between age squared and quality of life. However, self-mastery is not a mediator of the relationship between age squared and social participation. This final model is presented in Fig. 2 and had a good fit $\left(\chi^{2} / d f=1.332, \mathrm{CFI}=.950, \mathrm{RMSEA}=.059\right)($ Fig. 2$)$. The proportion variance explained for self-mastery was $39 \%$, for social participation $50 \%$, and for quality of life $81 \%$.

\subsection{Qualitative Study}

The focus of the qualitative study was to gain deeper knowledge of self-mastery and its importance in enhancing social participation and quality of life. We also explored promoting and impeding factors for self-mastery.

\subsubsection{Nodes and Themes}

We derived the following nodes from the qualitative data (Table 4): (1) Living conditions: factors that are associated with the residential situation; (2) Goals: long- and short-term goals related to the personal trajectory; (3) Daily structure: including daily activities and the meaningfulness of these; (4) Experiences with care: including expectations about the support of the shelter facility and the importance of the client-worker relationship; (5) Impeding factors: general factors that hinder self-mastery; (6) Internal locus of control: the belief in one's ability to cope with stressful or challenging demands (Rotter 1996); (7) Health: physical and psychological health, including coping with addiction; (8) Household chores: activities related to the regular work of a household; (9) External locus of control: a 


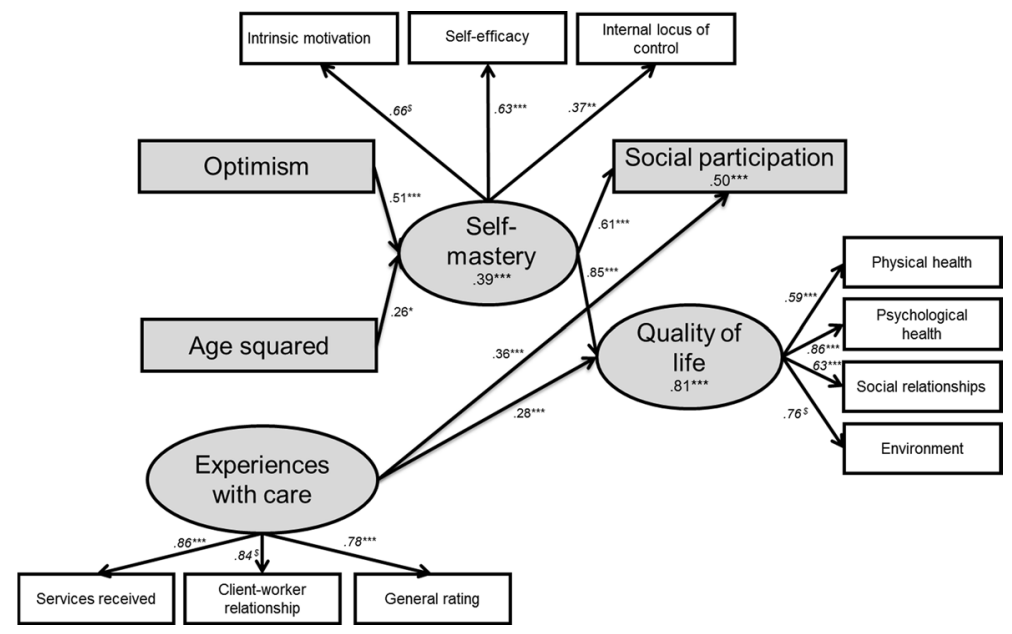

Fig. 2 Final model of self-mastery. Note Self-mastery does not mediate the age squared - social participation relationship. Standardized regression coefficients are shown next to the arrows, and factor loadings are printed in italics. Proportions of variance explained are reported below construct names. Ovals represent latent variables and rectangles represent observed variables. ${ }^{*} p<.05$. $* * p<.01$. ${ }^{*} * *<.001 .{ }^{\$}$ Loading fixed at the value of 1 in the non-standardized solution

negative belief in one's ability to cope with stressful or challenging demands (Rotter 1996); (10) Promoting factors: general factors that enhance self-mastery; (11) Self-efficacy: the belief in one's ability to achieve goals including the belief in one's ability to cope with various stressful or challenging demands (Bandura 1977); (12) House rules: rules or agreements related to a residential setting; (13) Social contacts: topics related to social relationships and social support; (14) Financial resources: topics related to the financial situation of clients, including the lack of financial resources and debts; (15) Social participation: participation in society or community, including labor-participation; (16) Intrinsic motivation: the desire to act in a certain way because it is interesting and satisfying in itself (Deci and Ryan 1985); and (17) Autonomy: (the ability of) making own decisions.

We clustered these nodes into themes (Table 5) that were formulated based on the structure of the hypothesized model: (1) Self-mastery: A combination of internal locus of control, the absence of external locus of control, self-efficacy, and intrinsic motivation; (2) Outcomes of self-mastery: Health (physical and psychological) and social participation.; and (3) Promoting and impeding factors for self-mastery: Living conditions, daily structure, experiences with care, health, house rules, financial resources, social participation, and autonomy. The nodes goals and household chores were not included in one of the themes, because they were not directly related to the model, but to the specification of selfmastery in the interviews (i.e., personal trajectory and living situation).

\subsubsection{Theme 1: Self-Mastery}

Our results showed that locus of control, self-efficacy, and intrinsic motivation were all found to be important aspects of self-mastery among most of the respondents (Rotter 1966; Bandura 1977; Deci and Ryan 1985). Specifically, the employment of internal locus of control in self-mastery was indicted by 33 respondents (170 references). For example, a participant reported: 


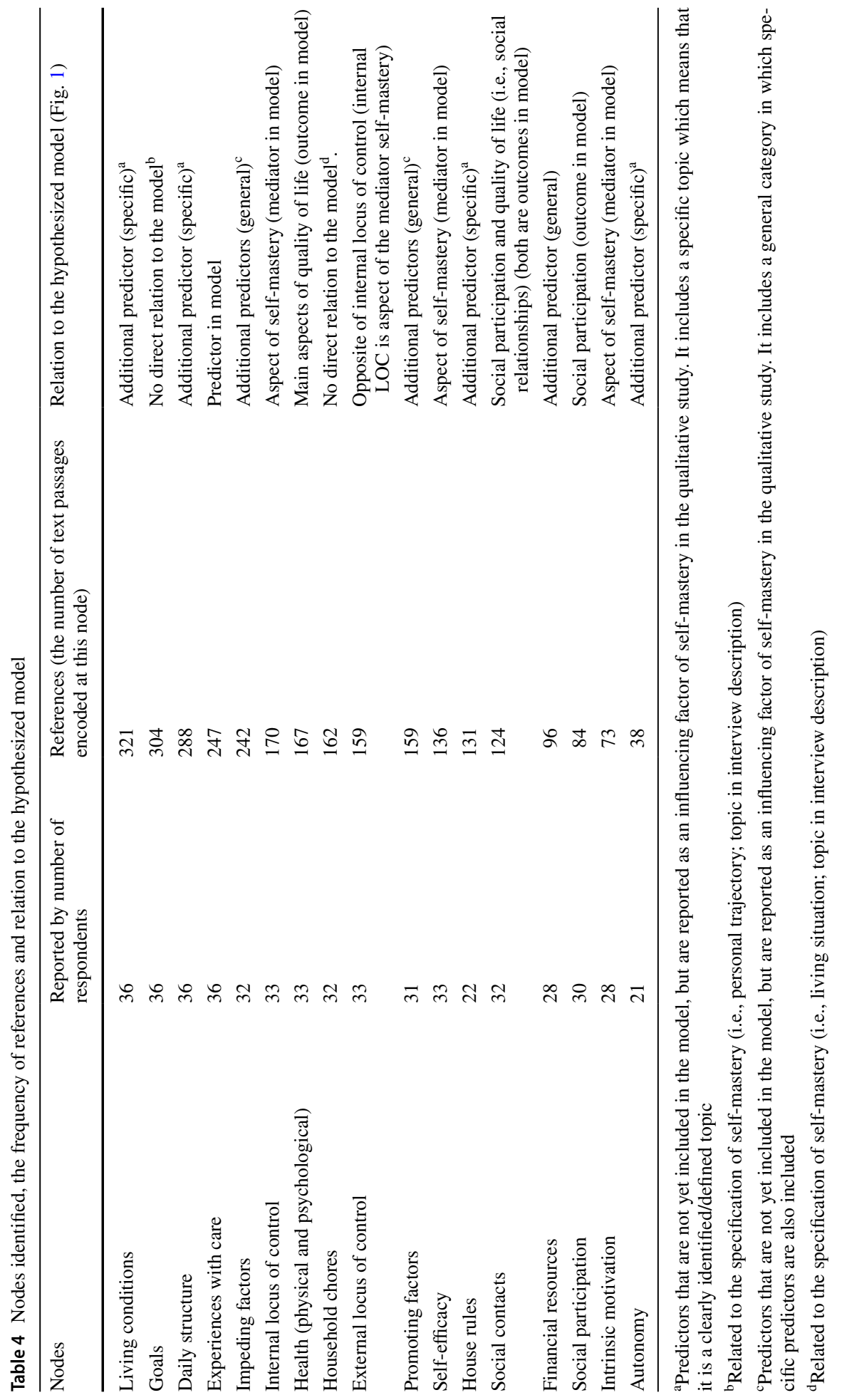


Table 5 Themes derived from nodes

\begin{tabular}{|c|c|}
\hline Themes & Nodes \\
\hline Self-mastery & $\begin{array}{l}\text { Internal locus of control } \\
\text { External locus of control (negative } \\
\text { association with self-mastery) } \\
\text { Self-efficacy } \\
\text { Intrinsic motivation }\end{array}$ \\
\hline $\begin{array}{l}\text { Promoting and impeding factors } \\
\text { for self-mastery }\end{array}$ & $\begin{array}{l}\text { Living conditions } \\
\text { Daily structure } \\
\text { Experiences with care } \\
\text { Health } \\
\text { House rules } \\
\text { Financial resources } \\
\text { Social participation } \\
\text { Autonomy }\end{array}$ \\
\hline Outcomes of self-mastery & $\begin{array}{l}\text { Health (physical and psychological) } \\
\text { Social participation }\end{array}$ \\
\hline
\end{tabular}

Yes, it is actually chanting, singing according to a Buddhist/Japanese way, that is actually very beautiful. You can learn from every mistake you make. You can make a new decision every time. You can choose any moment to look ahead instead of backwards. Yes, I have benefited a lot from it, despite my addiction (Respondent 12, 45-year-old male).

And another participant reported:

With regard to the budget course, I joined that course [budget course] because you must also be able to handle your financial situation. So that's why I took the course. So, in the future if I have to be independent regarding my finances, then I am willing to do that, I have no problems with that (Respondent 6, 60-year-old male).

External locus of control also seemed to play an important role as a negative aspect of selfmastery as reported by 33 respondents (159 references). An illustration:

I should work. But I also look at my age and that is going to be a tricky one, especially now that I haven't worked for more than 5 years. Go and tell a boss how it is possible that you have not worked for so many years. I also visited the UWV [Employee Insurance Agency]. They said: Yes, but ma'am, you can learn that again. I said: look at my age. UWV: yes, there is nothing wrong with it, there is enough work. I said: no, it must be work that suits me. Because when I go to work, I don't get a regular job (Respondent 13, 44-year-old female).

And another respondent illustrated external locus of control as follows:

It does not make sense, I have worked in geriatrics for about 20 years. You can make as many plans as you want to and look ahead as much as you want, but your body determines your health. You can stay on your path to accomplish your goals but you will be frustrated by circumstances that are beyond your control (Respondent 5 , 63-year-old male). 
Thirty three respondents (136 references) indicated the relevance of self-efficacy in selfmastery. Some illustrations:

Maybe later when they say well you go your own way well and we trust you, and then you have to pay that bill yourself, yes then I am able to do that. Yes, I have no problems with that (Respondent 6, 60-year-old male).

Despite the alcohol addiction, you keep bearing that name "alcoholic". But I did go to the institute for addiction for guidance. And I completely got rid of it and now and then I sometimes drink a beer, but I'm in control. I don't have to worry about having a hangover in the morning (Respondent 31, 48-year-old male).

Intrinsic motivation was found to be important aspect of self-mastery in 28 respondents (73 references). For example, a respondent reported:

But again I just don't want to worry about that. Then I'd rather grab a bucket of soapy water and go and clean the toilets, and yes, that certainly gives me a good feeling and it's clean and tidy again. And those who don't want to do it, that's not my problem, I am living here (Respondent 3, 55-year-old male).

\subsubsection{Theme 2: Outcomes of Self-Mastery}

A majority of the respondents reported that self-mastery is important for the improvement of their social participation; in 30 interviews the topic of social contacts was mentioned in relation to self-mastery ( 84 references). A respondent illustrated this as follows:

Yes, I am thinking about these things. I am already quite old and to find work is very difficult now for me, so that's why I do activities, to participate in society again and to get to know people (Respondent 6, 60-year-old male).

We also found that self-mastery is important in enhancing physical and psychological health (including coping with addiction) in our respondents (33 respondents mentioned health in relation to self-mastery; 167 references). In the hypothesized model quality of life was included as an outcome, but in the interviews this was not specifically reported, but the afore mentioned concepts of physical and psychological health are two basic aspects of quality of life (WHO 1998). An example:

I think it is related to my past, because when I visited a mental health care institution, it turned out that I had PTSD and a slight form of borderline, and something else. So, I was dealing with serious aggression problems then. But I have all that under control. So I'm happy about that (Respondent 7, 57-year-old male).

Social contacts were also associated with self-mastery which is a third aspect of quality of life and this concept is also related to social participation (WHO 1998). Specifically, 32 respondents mentioned the topic of social contacts (124 references). Two examples related to the meaning of social contacts:

Both of them [children] are from a different mother. I had no contact at all with my daughter. After 24 years we spoke each other again and I told my story and the first thing she said "you did well". Well, at that moment she called me daddy for the first time (Respondent 21, 58-year-old male). 
Yes, they do support me, so that's why I think it's important if you can be with other people, you know? That's always good, because when you're alone, you can't talk to yourself, you know? So that's why I think it's important to have social contacts (Respondent 6, 60-year-old male).

\subsubsection{Theme 3: Promoting and Impeding Factors}

We found that living conditions (mentioned in all 36 interviews; 321 references), daily structure (36 interviews; 304 references), experiences with care (36 interviews; 247 references), health (33 interviews, 167 references), house rules (22 interviews; 131 references), financial resources (28 interviews; 96 references), social participation (30 interviews; 84 references), and autonomy ( 21 interviews; 38 references) were all associated with self-mastery. Specifically, most respondents reported factors that are mostly considered as circumstances that they do not have control over, such as non-supportive house rules, a lack of financial resources, and not feeling at home in a residential shelter, as impeding factors for self-mastery. For example, a respondent reported:

It depends on the diversity of people who live here, the lack of privacy, the need to heed the rules, not being free to choose what you want to do or don't want to do. So, we are too close together to make you feel comfortable, I do not feel at home (Respondent 5, 63-year-old male).

However, the reported promoting factors can be seen as circumstances that clients feel they have (some) control over. Hence, a majority of the respondents considered their daily structure, the autonomy to decide how to spend their day, and their privacy as promoting factors. A respondent reported:

In comparison with the short-stay shelter, here you have a private room that you can go to. If you close the door... they leave you alone (Respondent 1, 42-year-old male).

Regarding experiences with care clients reported that the social/community worker who supported the client can be considered as either a promoting or impeding factor for self-mastery. Especially the delivery of fast and tailored care is considered positively. A respondent reported:

I even got a new mentor. I had insisted on this, and yes, she [the former mentor] actually impeded me in my recovery or in my opportunities to grow, and thus in the process of taking control of my life... I was allowed to choose who would be my mentor. It is very interesting that not everyone is allowed to do so. I had been around for so long that I had 6 different mentors. Well, I was tired of these changes (Respondent 30, 27-year-old female).

Considering the association between self-mastery and social participation, several respondents also reported that they experienced that work-related participation impedes self-mastery. Specifically, being unable to work (e.g., due to health problems) or being unable to find a job is considered to be problematic but also as something the clients feel is beyond their control. A respondent illustrated this as follows:

Since the last 2 months I do not work anymore. Two to three months ago I had a job and I worked for different companies, but now I am very ill due to COPD. I also had pneumonia. I cannot do anything anymore and had to give up my job (Respondent 34, 60-year-old male). 
We also found that health can also be considered a impeding factor for self-mastery. Respondents reported that due to health problems they were unable to master their lives. A respondent reported:

Yes, sometimes I have no peace of mind, I am anxious and I cannot do my things [household chores], cook, sweep, that will not work if I am so restless. Then it is as if the demons are talking to me and then I cannot do things like that (Respondent 3, 55-year-old male).

And another respondent said:

When things are going well, you want to take responsibility regarding your financial situation and you manage to do so, but that is not the case when you have a relapse [alcohol-addiction] (Respondent 12, 45-year-old male).

This implicates that social participation and health can also be considered as influencing factors of self-mastery (next to outcomes of self-mastery).

\subsubsection{New Insights}

The qualitative results yielded new insights regarding the theoretical framework, presented in the hypothesized model (Fig. 1). Additional findings related to our hypothesized model are (1) the absence of external locus of control should also be included as an aspect of self-mastery (external locus of control was mentioned in 33 interviews; 157 references); (2) several promoting and impeding factors should be included into the model, namely living conditions, daily structure, health, house rules, financial resources, social participation, and autonomy. The qualitative data did not directly indicate that optimism plays a role in enhancing self-mastery (optimism was not derived as a node from the qualitative data). We can speculate that is it hard to examine optimism in relation to self-mastery by conducting an interview. Finally, physical and psychological health seemed to be more important than the whole concept of quality of life.

\section{Conclusion and Discussion}

\subsection{Conclusion}

The current research investigated associations between person-related (i.e., optimism, age, education level) and care-related (i.e., experiences with care, duration of support) variables as predictors of social participation and quality of life through the mediator of self-mastery among clients of a Dutch homeless shelter facility (i.e., SMO Breda e.o.). Quantitative analysis showed that self-mastery is correlated with social participation and quality of life. Optimism predicts social participation and quality of life through self-mastery. Additionally, age squared predicts quality of life through self-mastery, but is not related to social participation. However, our hypothesized model is only partially confirmed in the quantitative study, because (1) clients' experiences with care is not related to self-mastery, but directly to social participation and quality of life; (2) education level does not predict social participation and quality of life directly, nor through the mediator of self-mastery; (3) nor did duration of support. The qualitative results yielded new and additional insights:

(1) Contrary to the results of the quantitative study qualitative data indicated that there 
is a positive association between experiences with care and self-mastery; (2) Both social participation and (aspects of) quality of life (i.e., physical and psychological health) are associated with self-mastery. These relationships seem to be circular. For example, losing a job for health reasons (i.e., one aspect of quality of life) gives people the feeling of having less control over their life which in turn affects their quality of life; (3) The absence of external locus of control should also be included as an aspect of self-mastery; (4) Clients reported additional promoting factors for self-mastery, such as daily structure, the autonomy to decide how to spend their day, and privacy; and they reported several impeding factors, such as non-supportive house rules, a lack of financial resources, and a sense of not feeling at home.

\subsection{Discussion}

We first discuss the results of the confirmed relations we found in the current study and then we discuss the findings on the non-confirmed relations. Finally, we discuss the additional (innovative) findings of the qualitative study.

\subsubsection{Confirmed Relations}

First, the in our research confirmed correlations between (1) self-mastery and social participation and (2) self-mastery and quality of life is in line with previous studies. The founders of "The Strengths Model" (Rapp and Gosch 2012; first edition of their work is from 1997) already emphasized the importance of self-mastery, for example the principle that the client is the director of his own trajectory and the importance of aspirations including beliefs and having confidence that they can be achieved in a positive manner (which is closely related to concepts such as intrinsic motivation, self-efficacy, and internal locus of control). In their "Theory of Strengths" self-mastery is related to an enhanced quality of life which also includes major aspects of social participation and social functioning, such as, being surrounded and supported by friends and companions. This means that our findings are emphasizing the importance of the knowledge on self-mastery that is included in strength-based and recovery-oriented approaches, because self-mastery also enhances quality of life and social participation among individuals experiencing homelessness.

Second, our quantitative study confirmed the relation between optimism and quality of life through the mediator of self-mastery. Previous studies already showed that optimism is positively correlated with (components of) self-mastery (Marshall and Lang 1990; GruberBaldini et al. 2009; Posadzki et al. 2010). However, these studies were conducted among other target groups and to our knowledge our research is the first one that examines this relationship among individuals experiencing homelessness.

Third, our quantitative analysis showed that age squared predicts quality of life through the mediator self-mastery. This means that a positive relation between age and quality of life through self-mastery exits until a certain age. Older people may not have the desire or ability to master their life leading to a lower quality of life (Wallace and Pichler 2009; Eurostat 2010). There is also a lack of literature on this specific mediation-relationship. We already stated that age (squared) is related with several aspects of self-mastery (Woodward and Wallston 1987; Chubb et al. 1997) and with quality of life (Diener 2009). Hence, our study contributes to the understanding of the relationship between age, self-mastery, and quality of life. 
Finally, qualitative analysis showed that experiences with care are associated with selfmastery. Clients described how a good bond with the social worker can enhance their levels of self-mastery, especially in combination with fast and tailored care. This indicates that client values (e.g., autonomy, fairness, and comprehensiveness) need to be recognized, as these values play a central role in tailored care (Schoot et al. 2005).

\subsubsection{Non-Confirmed Relations}

Regarding the non-confirmed relations, we have three discussion points. First, self-mastery did not mediate the relationship between age squared and social participation. Although age squared was positively related with self-mastery, it was not indirectly related to social participation. This is surprising, especially since we found that quality of life was related to age squared through self-mastery. As already stated the relationship between age squared on the one hand and quality of life and social participation on the other hand in relation to self-mastery should be further explored in future research.

Second, we also did not find a relationship between education level and self-mastery, nor between education level and social participation, and not between education level and quality of life in contrast to previous research (Forbes 2001; Dalgard et al. 2007; Rutenfrans-Stupar et al. 2019a). However, in previous research self-mastery, social participation, and quality of life were measured using different measures or constructs. Hence, future research is needed to confirm or reject the hypothesis whether education level is a determinant of self-mastery, social participation, and quality of life.

Third, duration of support also was not associated with self-mastery, social participation or quality of life. We expected that clients with longer duration of support would have lower levels of self-mastery, social participation, and quality of life, because of complex care demands and a higher risk of hospitalization. Clients with longer duration of support might have more complex problems compared to those with a shorter duration of support, but the latter group mostly deals with more urgent problems (e.g., dealing with becoming homeless and adapting to the new situation). Additionally, we can speculate that clients with longer duration of support did not feel institutionalized and were not in a phase of becoming lethargic with regard to their personal recovery. The shelter facility where the current research was conducted had adopted strength-based and recovery-oriented approaches (Rapp and Goscha 2012; Den Hollander and Wilken 2013; Wolf 2016), which may have led to reducing the risks of institutionalization for clients. However, to examine this further research is required.

\subsubsection{Additional Findings}

Finally, some remarks related to an extension of our model, we found that clients reported several promoting and impeding factors. In summary, qualitative findings added the following client-related predictors to our model: Physical and psychological health, social participation, financial resources, a sense of feeling at home, and privacy (the last two aspects can also be viewed as care-related predictors). They also added the following carerelated variables: Daily structure, the autonomy to decide how to spend the day, and house rules. In our view these factors contribute to the presented model, because they are related to clients' daily activities and both clients and social workers can have an influence on these factors. Strength-based and recovery-oriented approaches pay explicit attention to these factors (Rapp and Goscha 2012; Den Hollander and Wilken 2013; Wolf 2016). For 
example, physical and psychological functioning, social participation, financial situation, living conditions, and daily activities, are included as major topics in formats for recovery plans and strengths assessments that are frequently used by organizations that use these approaches (Rapp and Goscha 2012; Den Hollander and Wilken 2013; Wolf 2016).

Besides, we found that a lower or the absence of external locus of control also should be included in the concept of self-mastery. In the quantitative part of our study we used the LOC scale (Rotter, 1966) in which internal locus of control is the opposite of external locus of control. Hence, these two constructs are not divided into separate subscales which means that we included this concept in our analysis. However, when using other scales or questionnaires attention must be paid on the operationalization of locus of control in relation to self-mastery.

\subsection{Limitations of our Study}

Our study has some limitations. First, we used a cross-sectional study design. To test causal relationships between variables it is recommended to use longitudinal data. Second, we conducted the current research within the context of one shelter facility. To increase the transferability of the results, a multi-site research is needed. Third, although the participants formed an accurate representation (in terms of demographic variables) of the population of clients of the shelter facility, the currently used sample techniques have some limitations. Convenience sampling, used in the quantitative study, is vulnerable to hidden biases and we do not know whether the sample is representative in terms of scores on the questionnaires used in the current research (related to self-mastery and its outcomes and content-wise predictors). Purposive sampling, used in the qualitative study, is also vulnerable to selection bias, because the interviewers had influence on the choice of participants (Etikan 2016). Fourth, despite we assessed whether the current samples (of the quantitative and qualitative study) were representative compared to the population of clients of the shelter facility researched in the current study in terms of demographic variables, we did not compare the current samples to the whole homeless population in the Netherlands or broader. In the Netherlands and in other European countries comparable figures are not available because every country has its own system to report the number of homeless people (e.g., in some figures residential clients are not included) (e.g., Demaerschalk et al. 2018), and therefore we could not make a reliable comparison to assess the representativeness of our samples. Fifth, other factors might influence social participation and quality of life, such as ethnicity (Vaughan et al. 1985; Michalos and Zumbo 2001) and employment status (Vaughan et al. 1985). We did not include these variables in our research, but it is recommended to include these kind of variables in future research. Finally, we used general questionnaires to measure self-mastery in the quantitative study, but in the qualitative study, we specified the concept of self-mastery to self-mastery in the living situation and the personal trajectory. Therefore, one has to be cautious about drawing conclusions on self-mastery related to other life areas. All in all, for future research we recommend conducting a multi-site longitudinal study in which a distinction is made between specified self-mastery (such the living situation and personal trajectory) and general self-mastery.

\subsection{Implications for Practice}

The current study yielded insights regarding predictors and outcomes of self-mastery. Self-mastery is a basic aspect of strength-based and recovery-oriented approaches (e.g., 
Den Hollander and Wilken 2013; Korevaar and Dröes 2016; Wolf 2016; Rutenfrans-Stupar et al. 2019b). Our study highlights the importance of enhancing self-mastery among clients, because it seems to enhance social participation and quality of life. Therefore, it is important that social workers make use of the knowledge on self-mastery that these approaches provide. This is especially relevant, seeing how our research indicates that social workers play an important role in enhancing clients' social participation and quality of life, and probably also in enhancing their self-mastery by building a good client-worker relationship, being clear about the expectations regarding the care provided (also about the duration of activities related to the care), and by truly focusing on the needs and values of clients (tailored care).

Based on the insights produced by the current research, we have formulated practical recommendations for social and mental health-care workers to help enhance self-mastery among their clients. These recommendations include (1) working on a positive attitude among clients, which can be facilitated by enhancing strengths and talents; (2) creating an environment that makes the clients feel home, where privacy is taken into account and house rules are formulated together with clients; (3) providing for a daily structure in which clients are enabled to make their own choices and to work on their physical and psychological health and to acquire financial resources. The latter can be facilitated by stimulating clients to participate in educational, recreational, and work activities that focus on their health (e.g., sports activities will enhance physical and psychological health; Randers et al. 2011; Sherry and O'May 2013) and on their financial situation (e.g., a course to deal with debts or finding a job) (Rutenfrans-Stupar et al. 2019c).

Acknowledgements The authors thank all participants involved in this study and the employees of the shelter facility for their contribution to this research. We also thank Rick van Dun, Dirk Nieuwburg, Esra Gürcü, Emma Stieger, Naomi Vellekoop for their assistance with the data collection.

\section{Compliance with Ethical Standards}

Conflict of interest The first author of the paper is, and second author of the paper was, employed by SMO Breda e.o., the shelter facility where the research was conducted. However, the management board of SMO Breda e.o. had no role in the study design, the collection, analysis, and interpretation of data, nor in the content of the paper. Furthermore, the employment conditions of these two authors are fully independent of the content and publication of the current paper.

Open Access This article is distributed under the terms of the Creative Commons Attribution 4.0 International License (http://creativecommons.org/licenses/by/4.0/), which permits unrestricted use, distribution, and reproduction in any medium, provided you give appropriate credit to the original author(s) and the source, provide a link to the Creative Commons license, and indicate if changes were made.

\section{References}

Applebaum, A. J., Stein, E. M., Lord-Bessen, J., Pessin, H., Rosenfeld, B., \& Breitbart, W. (2013). Optimism, social support, and mental health outcomes in patients with advanced cancer. Psycho-Oncology, 23, 299-306.

Arbuckle, J. L. (2013). IBM SPSS Amos 22 user's guide. New York, NY: IBM.

Awang, Z. H. (2012). A handbook on SEM. Shah Alam: UiTM.

Bandura, A. (1977). Self-efficacy: Toward a unifying theory of behavioral change. Psychological Review, $84,191-215$.

Beijersbergen, M. D., Christians, M., Asmoredjo, J., \& Wolf, J. R. L. M. (2010). De CQ-index voor de maatschappelijke opvang, vrouwenopvang en zwerfjongerenopvang: Ontwikkeling van een 
meetinstrument voor cliëntervaringen met de opvang [The CQ-index for organizations providing shelter and support for homeless people including women and youth: Development of an instrument for measuring clients' experiences with care]. Nijmegen, Netherlands: UMC St Radboud.

Blunch, N. J. (2013). Introduction to Structural Equation Modeling using IBM SPSS statistics and Amos. Los Angeles, CA: SAGE.

Byrne, B. M. (2016). Structural equation modeling with amos. New York, NY: Routledge.

Chubb, N. H., Fertman, C. I., \& Ross, J. L. (1997). Adolescent self-esteem and locus of control: A longitudinal study of gender and age differences. Adolescence, 32, 113-129.

Creswell, J. W., \& Plano Clark, V. L. (2011). Designing and conducting mixed methods research. Los Angeles, CA: SAGE.

Dalgard, O. S., Mykletun, A., Rognerud, M., Johansen, R., \& Zahl, P. H. (2007). Education, sense of mastery and mental health: Results from a nation wide health monitoring study in Norway. BMC Psychiatry, 7 , 1-9.

De Vries, J., \& Van Heck, G. L. (1996). Nederlandse WHOQoL-Bref. TilburgNetherlands: Tilburg University.

Deci, E. L., \& Ryan, R. M. (1985). Intrinsic motivation and self-determination in human behavior. New York, NY: Plenum.

Demaerschalk, E., Italiano, P., Mondelaers, N., Steenssens, K., Schepers, W., Nicaise, I., et al. (2018). Measuring Homelessness in Belgium. Brussels: Belgian Science Policy.

Den Hollander, D., \& Wilken, J. P. (2013). Zo worden cliënten burgers: Praktijkboek Systematisch Rehabilitatiegericht Handelen [This is how clients become citizens: Practical book for Systematic RehabilitationOriented Acting]. Amsterdam: SWP.

Diener, E. (2009). Subjective well-being. In E. Diener (Ed.), The science of well-being (pp. 1-10). Dordrecht: Springer.

Enders, C., \& Bandalos, D. (2001). The relative performance of full information maximum likelihood estimation for missing data in structural equation models. Structural Equation Modeling: A Multidisciplinary Journal, 8, 430-457.

Etikan, I. (2016). Comparison of convenience sampling and purposive sampling. American Journal of Theoretical and Applied Statistics, 5, 1-4.

Eurostat (2010). Social participation and social isolation. Retrieved from http://ec.europa.eu/eurostat/web/ products-statistical-working-papers/-/KS-RA-10-014

Feantsa (2005). ETHOS: European typology on homelessness and housing exclusion. https://www.feantsa.org/ en/toolkit/2005/04/01/ethos-typology-on-homelessness-and-housing-exclusion.

Forbes, D. A. (2001). Enhancing mastery and sense of coherence: Important determinants of health in older adults. Geriatric Nursing, 22, 29-32.

Gruber-Baldini, A. L., Ye, J., Anderson, K. E., \& Shulman, L. M. (2009). Effects of optimism/pessimism and locus of control on disability and quality of life in Parkingson's disease. Parkinsonism \& Related Disorder, $15,665-669$.

Guay, F., Vallerand, R. J., \& Blanchard, C. (2000). On the assessment of situational intrinsic and extrinsic motivation: the Situational Motivation Scale (SIMS). Motivation and Emotion, 24, 175-213.

Hayes, N. (2000). Doing psychological research: Gathering and analysing data. Buckingham: Open University Press.

Kan, C., Kawakami, N., Karasawa, M., Love, G. D., Coe, C. L., Miyamoto, Y., et al. (2012). Psychological resources as mediators of the association Between social class and health: Comparative findings from Japan and the USA. International Journal of Behavioral Medicine, 21, 53-65.

Knoop, R. (1981). Age and correlates of locus of control. The Journal of Psychology, 108, 103-106.

Korevaar, L., \& Dröes, J. (2016). Handboek rehabilitatie voor zorg en welzijn: Ondersteuning van maatschappelijke participatie en herstel [Handbook rehabilitation for care and well-being: Support for social participation and recovery]. Bussum: Coutinho.

Kruize, A., \& Bieleman, B. (2014). Monitor dakloosheid en chronische verslavingsproblematiek [Monitor homelessness and chronic substance abuse]. Groningen: Intraval.

Little, R. J. A. (1988). A test of missing completely at random for multivariate data with missing values. Journal of the American Statistical Association, 83, 1198-1202.

Luszczynska, A., Scholz, U., \& Schwarzer, R. (2005). The General Self-Efficacy Scale: Multicultural validation studies. The Journal of Psychology, 139, 439-457.

Marshall, G. N., \& Lang, E. L. (1990). Optimism, self-mastery, and symptoms of depression in women professionals. Journal of Personality and Social Psychology, 59, 132-139.

McColl, M. A., Davies, D., Carlson, P., Johnston, J., \& Minnes, P. (2001). The community integration measure: Development and preliminary validation. Archives of Physical Medicine and Rehabilitation, 82, 429-434.

McQuistion, H. L., Gorroochurn, P., Hsu, E., \& Caton, C. L. M. (2013). Risk factors associated with recurrent homelessness After a first homeless episode. Community Mental Health Journal, 50, 505-513. 
Michalos, A. C., \& Zumbo, B. D. (2001). Etnicity, modern prejudice and the quality of life. Social Indicators Research, 53, 189-222.

Pearlin, L. I., \& Schooler, C. (1978). The structure of coping. Journal of Health and Social Behavior, 19, 2-21.

Planije, M., Tuynman, M., \& Hulsbosch, L. (2014). Monitor plan van aanpak maatschappelijke opvang: Rapportage 2013/'14 [Monitor plan of approach for homeless social services: Report 2013/'14]. Utrecht: Trimbos Instituut.

Posadzki, P., Stockl, A., Musonda, P., \& Tsouroufli, M. (2010). A mixed-method approach to sense of coherence, health behaviors, self-efficacy and optimism: Towards the operationalization of positive health attitudes. Scandinavian Journal of Psychology, 51(3), 246-252.

Randers, M. B., Petersen, J., Andersen, L. J., Krustrup, B. R., Hornstrup, T., Nielsen, J. J., et al. (2011). Shortterm street soccer improves fitness and cardiovascular health status of homeless men. European Journal of Applied Physiology, 112, 2097-2106.

Rapp, C. A., \& Goscha, R. J. (2012). The strengths model: A recovery-oriented approach to mental health services. New York: Oxford University Press.

Rappaport, J. (1987). Terms of empowerment/exemplars of prevention: Toward a theory for community psychology. American Journal of Community Psychology, 15, 121-148.

Rijksoverheid (2013). Troonrede 2013 [King's speech 2013]. Retrieved from https://www.rijksoverheid.nl/ documenten/toespraken/2013/09/17/troonrede-2013

Rotter, J. B. (1966). Generalized expectancies for internal versus external control of reinforcement. Psychological Monographs: General and Applied, 80, 1-28.

Rutenfrans-Stupar, M., Van Regenmortel, T., \& Schalk, R. (2019a). How to enhance social participation and well-being in homeless clients: A structuralequation modelling approach. Social Indicators Research, 145, 329-348.

Rutenfrans-Stupar, M., Schalk, R., \& Van Regenmortel, T. (2019b). Growth Through Participation: A longitudinal study of a participation-basedintervention for (formerly) homeless people. Journal of Social Service Research. Advance online publication.

Rutenfrans-Stupar, M., Van der Plas, B., Den Haan, R., Van Regenmortel, T., \& Schalk, R. (2019c). How is participation related to well-being of homelesspeople? An explorative qualitative study in a Dutch homeless shelter facility. Journal of Social Distress and the Homeless, 28, 44-55.

Scheier, M. F., Carver, C. S., \& Bridges, M. W. (1994). Distinguishing optimism from neuroticism (and trait anxiety, self-mastery, and self-esteem): A re-evaluation of the Life Orientation Test. Journal of Personality and Social Psychology, 67, 1063-1078.

Schoot, T., Proot, I., ter Meulen, R., \& Witte, L. (2005). Recognition of client values as a basis for tailored care: the view of Dutch expert patients and family caregivers. Scandinavian Journal of Caring Sciences, 19, $169-176$.

Schou, I., Ekeberg, Ø., \& Ruland, C. M. (2005). The mediating role of appraisal and coping in the relationship between optimism-pessimism and quality of life. Psycho-Oncology, 14, 718-727.

Schreiber, J. B., Nora, A., Stage, F. K., Barlow, E. A., \& King, J. (2006). Reporting structural equation modeling and confirmatory factor analysis results: A review. The Journal of Educational Research, 99, 323-338.

Schwarzer, R., \& Jerusalem, M. (1995). Generalized Self-Efficacy scale. In J. Weinman, S. Wright, \& M. Johnston (Eds.), Measures in health psychology: A user's portfolio. Causal and control beliefs (pp. 35-37). Windsor: NFER-Nelson.

Sherry, E., \& O'May, F. (2013). Exploring the impact of sport participation in the Homeless World Cup on individuals with substance abuse or mental health disorders. Journal of Sport for Development, 1, 1-11.

Teddlie, C., \& Tashakkori, A. (2009). Foundations of mixed methods research: Integrating quantitative and qualitative approaches in the social and behavioral sciences. London: Sage.

Teeuw, B., Schwarzer, R., \& Jerusalem, M. (1997). Dutch adaptation of the General Self-Efficacy Scale. Retrieved from http://userpage.fu-berlin.de/ health/dutch.htm

Ten Klooster, P. M., Weekers, A. M., Eggelmeijer, F., Van Woerkom, J. M., Drossaert, C. H. C., Taal, E., et al. (2010). Optimisme en/of pessimisme: factorstructuur van de Nederlandse Life Orientation Test-Revised. Psychologie en Gezondheid, 38, 89-100.

Tuynman, M., \& Planije, M. (2012). Monitor plan van aanpak maatschappelijke opvang: Rapportage 2011 [Monitor plan of approach for homeless social services: Report 2011]. Utrecht: Trimbos Instituut.

Van Houten, G., Tuynman, M., \& Gilsing, R. (2008). De Invoering van de WMO: Gemeentelijk beleid in 2017 [The introduction of the Social Support Act: Community policies in 2017]. The Hague: Sociaal en Cultureel Planbureau.

Van Luijtelaar, M., \& Wolf, J. (2012). Participatie, empowerment en herstel; Een inventarisatie van meetinstrumenten [Participation, empowerment and recovery; An assessment of measurement instruments]. Nijmegen: UMC St Radboud. 
Van Regenmortel, T. (2002). Empowerment en maatzorg [Empowerment and customized care]. Leuven, Belgium: Acco.

Vaughan, D. A., Kashner, J. B., Stock, W. A., \& Richards, M. (1985). A structural model of subjective wellbeing: A comparison of ethnicity. Social Indicators Research, 16, 315-332.

Wallace, C., \& Pichler, F. (2009). More participation, happier society? A comparative study of civil society and the quality of life. Social Indicators Research, 93, 255-274.

WHO. (1998). WHOQOL user manual. Geneva: World Health Organization.

Wolf, J. (2016). Krachtwerk. Methodisch werken aan participatie en zelfregie [Strengths work. Methodological working on participation and self-direction]. Bussum: Coutinho.

Woodward, N. J., \& Wallston, B. S. (1987). Age and health care beliefs: Self-efficacy as a mediator of low desire for control. Psychology and Aging, 2, 3-8.

Zimmerman, M. A. (1995). Psychological empowerment: Issues and illustrations. American Journal of Community Psychology, 23, 581-599.

Publisher's Note Springer Nature remains neutral with regard to jurisdictional claims in published maps and institutional affiliations.

\section{Affiliations}

\section{Miranda Rutenfrans-Stupar ${ }^{1,2,3} \cdot$ Naomi Hanique $^{1,2,3} \cdot$ Tine Van Regenmortel $^{1,4}$. René Schalk ${ }^{1,5}$}

1 Tilburg School of Social and Behavioral Sciences, Tranzo, Tilburg University, PO Box 90153, 5000 LE Tilburg, The Netherlands

2 SMO Breda e.o, Breda, The Netherlands

3 Avans University of Applied Sciences, Breda, The Netherlands

4 Faculty of Social Sciences - HIVA, University of Leuven, Louvain, Belgium

5 Faculty of Economic and Management Sciences, North-West University, Potchefstroom, South Africa 